\title{
A new song cycle
}

Håkan Hagegård 
Ladies and Gentlemen, you are now about to attend the world première of a song cycle. It's a cycle of 10 songs, which is less than Schubert's "Winterreise" and more than Ravel's "Don Quijote". I would like to go song by song, and you are welcome to interrupt me after each one, if, for example, you don't like the tempo or if you don't like the tone of my voice.

\section{Song number one}

The first song in a recital program is - and Schubert didn't quite get this - supposed to be short. The first song in "Winterreise" is too long, too many verses, too much text.

In the first song I will remind you of what Danny Kaye did at a performance at the Metropolitan Opera. The performance was called "Look In" and was staged by the late Göran Gentele. The purpose was to get new audiences to the theatre. This time the house was filled with 3800 kids, and Danny Kaye entered in his beautiful shoes, as you may remember.

- Good morning, he said to the audience!

No reaction!

- Oh I am sorry, it's an Opera House.

He went out and came back on to the stage a second time and sang out "Good Mooooorning", and had an enormous "Good Morning" back from the kids. That is communication on a high level. Understanding what the situation is, whom you are talking too, who you are yourself, where you are ... From that moment he could tell the kids just anything, and they would believe him.

\section{Song number two}

It is slightly longer, because it has to do with who I am. I usually describe myself as "there is a life before 'The Magic Flute', and there is a life after "The Magic Flute'". I will not go into details about this magic flute, people know which instrument I'm talking about. It's of course Wolfgang Amadeus Mozart's "Magic Flute". There were suggestions actually, when Ingmar Bergman's film "The Magic Flute" was to released in Stockholm, that Mozart would get an award for taking part in it. It never happened, but that's the way the talk went.

I was born in Sunne, Värmland, and I grew up in Karlstad. My parents were very interested in music and so were my siblings. We learned how to speak through our instruments. We didn't talk a lot. We didn't solve problems at home by talking. We picked up our in- 
struments and we sang in order to solve them. I learned to communicate with an instrument very early, very early, indeed. It didn't really matter which instrument we grabbed. It could be a cello, it could be a piano, a flute, a clarinet, or just singing. This I mention because it's very important for my view on communication, on my view on how to use music to communicate with other people. You can bring a message from one point to an other with music.

I went to school, of course, and I did fairly well. Not terribly well, my degrees were not good enough to admit me to Chalmers in Gothenburg to study architecture. So I had to put that idea out of my mind, but, fortunately, one could at that time still do military service in Sweden. So I spent 15 months thinking about something else to do. After 15 months - and I probably used that time ineffectively - I still didn't know what to do with my life.

Music was still my only language, so I decided to go to Stockholm to try to enter the Academy of Music in Stockholm. To my surprise, I was accepted. So I said, all right, I'll stay around for a while and eventually I will find something else to do. After one year of phrasing Schubert and other Lieder composers, I was asked to attend an audition at the Opera House. I immediately went there, because I could smell money, money to pay my fees at the Academy.

I made my debut at the Opera House when I was 23, with nearly no schooling at all. I learned the job at the theatre, in different projects that I took part in and with the best teachers available. "The Magic Flute" with Ingmar Bergman was one of them, because he also invited me to attend, for two years, all his production meetings before the film was to be shot, and that was a very good school, indeed.

I see in my biography here that "he also sang at Carnegie Hall". I love that remark, because having made it all the way to Carnegie Hall is the criteria for ultimate success.

To talk about what I am, who I am, what I want, what my ideas of performing are, of communication and so forth is fairly new to me. It started when I was thinking about building a studio for myself. When I moved out to Värmland west of Stockholm and realized that there were a lot of people in my situation, artists, musicians, who also wanted to have their own studio and maybe an office and so on. So I began to think about building a complex that could host more artists than myself.

Why should a performer go into this ordeal of building a music centre? 
The idea was very exciting. I could well imagine the meeting place.

I could hear reports from around the world that the quality of performances were going down quite steeply. Certainly regarding Lieder recitals, but also opera. To travel around the world for a rehearsal in Europe and then perform in the States the same day to make as much money as possible is certainly bound to lower the quality of the performance. It made me worried. And I thought, maybe I will be out of job in 20 years. I'm not less worried today, but I think we have at least been able to focus on the problem.

Well, the music centre HageGården was built and that process gave me the opportunity to meet people in my own business and in its vicinity whom I had never met before. If I hadn't built the music centre I wouldn't have met you guys. I would still have been a performer, isolated in the dressing room and on stage. And I would have been in someone's studio working most likely with a pianist, coaching or trying to work out the parts that I was supposed to perform.

I felt at that time that the distance between performers and composers, was enormous. I didn't know where the composers were. I didn't know where they lived. I hardly knew in which room they were at the Academy, and if I knew where they were, I wouldn't have dared to knock on their door. I had an enormous respect for that Parnassus.

So I started my career, thinking that performers were the least important in the chain of communication. Much later, when I planned the music centre, I realized that, in order to raise the quality of performance, we need to focus on the performers themselves. We need to give them tools to develop their own performance skill, to give them more and better tools for artistic expression and a larger scale of expression. Then we might have a chance to improve artistic performance.

\section{I have come to song number three}

It is about Peter Oswold, for me a very important man. I met him through friends in San Francisco. He introduced me to his Health Program for Performing Artists. It consists of 20 doctors forming a group. When performing artists consult them, these doctors not only look at a pianist's hand or a cellist's back. They go through the whole person. It gave me a lot of ideas. Maybe it's not only what happens here, in the throat, that's important for a singer. 
Maybe it's just as much about what happens here in the head.

I left the Academy of Music in Stockholm, still under the impression - honestly - that singers were musicians of lesser rank. Other musicians were brilliant, organists fantastic, singers - well, give them a good dinner and maybe they will come to the rehearsal tomorrow, but just maybe. We hope they will. They might be too drunk, but still, they might show up.

This start-out as a performer was of course disastrous, it lowered my self-esteem enormously. When I met Peter Oswold, I began to think that something could be done about this. We started to talk about things like: what does the brain need to be creative? What does the brain need to think new thoughts? Really new thoughts. Not the old thoughts re-assembled and played backwards. I was very interested in what conditions would enhance creativity, and the first thing seemed to be the need to slow down. The brain needs to lower its speed for a special sugar to be produced in its centre for creativity. It's very practical.

OK, good! So all we need is a place where we can slow down. A place where the tempo is not as high as on Manhattan, or even in Kungsgatan in Stockholm. Thoughts like these also encouraged me to build a music centre.

We also need to create safety for the singers, for the performers, for the musicians. In order to be creative, you must be able to lock the door and thus keep the audience, which can sometimes act as a threat to the performer, at a distance. Then you can start to think new thoughts. Also lock the door to the press, the critics should not be able to make comments about every move we do.

I think that these basic conditions for performing arts are necessary for the future. We have to have these safety havens for performing artists who otherwise will be burnt out very quickly.

\section{Song number four}

It's about the double communication, issues that we already have been talking about. In my opinion, nothing happens in the concert hall until the audience starts to play, or the audience starts to act. Nothing happens until the audience starts to return what has been given to it. I call this the double communication. Maybe two-way communication would be a better expression for it, but what I mean is that performers up here on the stage can talk ever so much to the audience over there, but if performers don't make the audience understand what they are saying and start making what is said their own, the audience will never show us that it 
understands. Only when the performer can recognize that the audience understands, will he improve his performance. It is like climbing a staircase. I can, as a performer, lift the audience to a higher level of thinking, or - if you like - a higher level of perception. If I succeed in doing so, I can also climb up that one step. Having stayed there for a while I can ask the audience to climb even higher, to further refine its perception and in that way we might exchange questions and answers and finally - we meet. This is the moment in a concert when I feel that I have the audience. Now I don't need to do anything more. It's a very happy moment.

So, to me the action is very important, but the reaction is even more important. Actually, interaction is what we want. Interaction will make the audience feel that, hmm, I'm part of this!

And coming back to the discussions of what the essence is and what is the meaning, and what are we as interpreters allowed to do, I think that I could take it one step further. We are - that is my opinion - allowed to do almost whatever it takes to make the audience understand what we are doing. But we must not present the concert in a cheap way. Then we might feel prostituted.

These are some of the thoughts that we exchanged, Peter Oswold and I.

I should mention that Peter was also a psychiatrist as well as a violinist who played with, among others, Glenn Gould. He wrote a book about Gould and one about Schumann called "Genius and Madness in Music".

To make the audience understand what we are doing, we have to be - in practical terms - very precise about in what order we are presenting the subject. First of all we have to think right. We have to think the piece. It has to be here inside our head.

Then we can move our eyes and look at the audience and the audience will say: oh, here it's coming. That unifies the audience. They say, he's about to say something to us. Let's get together and see if we can get it. Then you can move your head and the audience says: alright, we are ready. Then you can start singing and the audience will understand what you are saying and what you are doing. If the singer does this in any other order, for instance starts to sing not having made quite clear to himself what song, whether this song or another song, he will find, when he looks around, the audience half asleep. I tell my students: thought, eyes, gesture, then sing. No other order.

The other thing that is very important for us when we talk 
about performing, is to keep a distance to the work. You are familiar with the thought that we are not supposed to cry or laugh on stage. It's the audience that is supposed to do that. But how can we avoid being affected by the music while we are performing it? The young students say, well, the more I feel the better it is, then the audience will understand. If I am really angry, then they will understand that I am angry. This is not true. If you are really angry, the audience will say: "Something is wrong with that guy". And they will ask for their money back.

A performer should communicate with the audience like this: he should have the entire audience in his view and he should focus on the entire audience. But there are different sizes of songs or roles and if you are supposed to perform a song that is this big and at the same time focus on the entire audience, you have to put the song at a certain distance from yourself. Otherwise it won't work. If you put the song too close, which means that you feel it inside, starting to communicate like that, spreading your message, your poor audience will get only a small portion of the piece.

There are singers who are more interested in the cheque after the concert than actually to communicate their message. No names. They put the song over here, very far away, and they start communicating that way, and it's only a small part of the audience that understands what you are doing. So one must find, and this is very important, during rehearsals the proper distance. OK. Now interrupt me and say stop.

NN: I did not get that.

$\mathrm{HH}$ : It has to do with putting the artist in control of the piece that he wants to perform. To do that, you have to have a distance to the piece itself. Otherwise you cannot manipulate the piece and thus manipulate the audience.

This technique or picture works well in a teaching situation, because students have to understand this. Students can transform this technique into their own performances. They say: "The piece itself, where does it come from? Does it come from within me or from what, from where?" Well, in order to create that distance, you must get rid of the guilt for the composer. You must not say to yourself: "Oh, I take the responsibility for the composer, I will do this the way he wants it." You can say: "He wrote the piece, let's blame him, he must be a part of whether the piece is a success or a failure." And when they hear this, all singers without exception say: "phew, wow! I thought I had to carry that burden alone." So I say: "We do not have eyes in the back of our head. Here comes 
the message. It should be filtered, interpreted, if you like, and go over to the audience."

To illustrate this procedure, I use the picture of the astral projection. On stage I step out of myself in my thought, put myself to the side of myself and observe myself and the whole sequence. From the composer, through the piece, the song, all the way to me, and watch how the message carries over to the audience. And being here, outside myself, I can keep an eye on the piece, how it was in the beginning, before I started destroying it, and I can keep an eye on the audience at the same time.

So, these two pictures together make it workable for also the performing artist, not only for students to understand what it's all about. I often clarify this in master classes with professional singers, and say: "If you think this way, it will be much easier for you to unload yourself. And, furthermore, you will get rid of a lot of fear." Guilt creates fear. So this is very much the source of stage fear.

Yes?

NN: That relates very much to Diderot's paradox, that the actor in a theatre should not cry or be angry himself.

$\mathrm{HH}$ : Right.

NN: - It's about awakening emotions in the audience, but not of representing them in yourself: Theodore speaks of being the messenger of the author, and being the messenger in special affair, of course, also about awakening, for awakening emotions or wakening meaning.

$\mathrm{HH}$ : It also works that way. I know this from my own experience. If a performer gets too involved in the piece, the audience will not believe in the message. Therefore, it's much better to create an image of what we are performing, a mask. We talk about a mask as theatre. Not only will the audience understand it better, because it is a lie. It's not reality. The audience wants to believe in the lie not in the reality. The mask also protects us, not to be swallowed up by the audience. If you can learn to use this method, you will last longer as a performer.

\section{The fifth song is about darkness and light}

I make a difference between performers who prefer darkness and performers who prefer light. I can see both types among my students, even when they are at a very early age, both the ones who want to see the audience in the eyes and the ones who do not.

Many students don't. They want a dark wall and they want to 
perform in closed rooms with their friends and fellow singers and - if it is an opera - their fellow actors.

Those who like light and want to see the reaction in the eyes of the audience when they sing a loud note or a soft note, who like to see if there is a reaction or no reaction, which means that they have to work harder, they are more likely to become concert singers and be very good in concert halls and on stages.

I have a short little story about this. I did a recital, I cannot remember where. There was this couple in the audience and it was clear that he had been working hard all day, because he fell asleep after two minutes. Zzzz, you know. I thought I was brilliant, but that didn't help. She had been home all day, she had beautiful make-up and she had her best dress and was very attentive. She was probably the one who had dragged him there. I thought I understood the picture, I have seen this situation many times. So I said to myself: hmm, I need to do something about this and started to sing to her a little bit more. Not in an obtrusive way, but inviting her, as if I was saying to her: it's good to see you here, are you free afterwards, and so on, until she got so embarrassed that she woke up her husband, and then I had them both, and I thought, yes, wonderful, we are having a concert here.

So, for me, it has always been much more fun to perform to an audience that I can see. I can see its reactions, I can register if the message is interesting to them. If the audience thinks that I am boring, then I know that the next concert should have less of this stuff. Thus I can form programs that can be really interesting, testing out sequences of programs and so on.

The visual part of the concert is a neglected part, I think. I'm not talking about dramatic performances like opera and musicals. I'm talking about concerts. There is a change going on these days, though. I know that orchestras have special training in entering the stage, coming on stage from two sides at the same time. It looks beautiful. Everybody is standing up, and then everybody is sitting down together. That immediately creates a communication and looks better than if they walk in with their violins and say: "Oh, there are people here!"

When it comes to Lieder recitals I have worked quite a lot in Oslo, at the academy there, to try to find out other ways of performing Lieder. I have also worked at the Indiana University in Bloomington on these subjects.

A year ago I did Wolf's "Italienisches Liederbuch" in a staged version with eight singers and four pianists. I must tell you that 
the first time I sent e-mail over to Indiana about this idea, including the list of songs and who should sing what, I had an answer from one of the teachers, saying "you don't really mean that she is going to sing this song which is always sung by a man? There must be a mistake! Could you please correct that and send it back."

I said, no, this is the way. I shall have on the set two laptops in two different rooms and she will be reading an e-mail from "him". Then I got an e-mail back from this teacher, saying, hmm, meaning of course that "This is new. I wonder if this is good."

I used this method, making very clear also to the students the importance of really understanding what they are singing about. To know exactly and in every detail where they are, when they are performing a song. To be aware of what they see, who they are singing to and all these subjects in a performance. It has a tremendously good effect on the singers that did that.

I am about to do a festival of Dominick Argentos' music, three song cycles in one evening with two intervals. That's quite a lot of music. It's like an opera. Dominick loves the idea and he is - as I am - absolutely sure that it is going to work. I am going to perform "The André Expedition", "A Few Words about Chekhov" and "From the Diaries of Virginia Woolf", all in one evening. I am very much looking forward to do this and I am going over to Bloomington on the 9 th of October to prepare it.

I get e-mails every day that tremble, meaning, what is he up to? But such undertakings are very exciting, taking the Lieder repertoire - hopefully lieder that are not yet written - into a concert hall and stage them a little. Although the audio part of the performance is in most cases enough, I truly believe that the audience today is so visually orientated, that if we don't give them something to follow with their eyes, there is a real risk of loosing them. They look at television, they look at computers, there is a lot of action in performances. So I don't think that I am wrong; I think we are starting opera all over again. And now I am talking about not only this room called the future, but the real future.

\section{We are now at song number six}

Who owns the artist? Who owns the rights of what the artist produces? I shall not try to answer the question, but I want to put it to you.

It has to do with copyrights, of course. Is the composer the owner of the piece that the artist is performing? Is the presenter, 
the one who hired the artist, the owner of the performance? Is the audience the owner of the artist, because it paid for the concert tickets? These are questions that I think we have to turn to in times to come to enable the artist to communicate the piece to the audience in the right way.

It is important that the artist does not feel prostituted. The artist should get paid, of course, but for the right thing, namely for the artist's original work and not for something the artist no longer recognises and which has been manipulated by others. When it comes to recordings this is a hot issue. Very often recording companies want to buy the rights with the intention of doing - eternally and in any medium - whatever they want. It is understandable that keeping track of every little song all over the world is very difficult, but how otherwise can an artist control his "product" and how it is treated.

\section{Song number seven}

The problem of singing old stuff versus singing new stuff. I don't know how much you can influence this, but I think that if we don't get more new stuff on stage, we are in big trouble. We cannot go on being a museum. We cannot join the forces with painters saying that my highest expectations and achievement is to hang my piece in a museum, where so and so many people will be able to see it. I think we have to make the music - and I think somebody said this earlier - a living art form. I therefore have started a project called "Free Speech in Music". This deals with present-day texts set to music. If, for instance, there was something written in yesterday's newspaper, it will be set to music today and performed tomorrow. That's very extreme.

We have to ask you composers to join us in this, for us composers and artists not to loose the audience.

\section{Now, number eight}

The question about interpretation. Is there room for interpretation? Certainly there is room for interpretation. Regarding songs there are no limits. If I sing a song slower one day and a little faster another day, it's because I have noticed in the audience that it is necessary to sing it faster. Otherwise the audience will not react, not answer. There is no absolute tempo there. There are also accents in the music that I have to alter due to circumstances; acoustics and reverberation have to be considered for the text to 
come out clearly. These things change considerably from one hall to another.

Somebody mentioned the pronunciation of words, where the composer has, deliberately or because he has not understood the words, put the accents on the wrong syllables. This occurs most often in music that was composed a while ago. As a performer, communicating with the audience today, I must feel free to change it in a way so as to communicate with the audience of today, not the audience of yesterday.

We also understand the poet better today than we did then. In that respect I think the performer, the artist, owns the right of the music to make it work. The very moment that he is loosing the audience because he is doing it in a certain way, he looses that right. Everybody agrees, I love it.

Now, there are composers who are very cruel. Like Berg. It took me a year to learn "Wozzeck" by heart. And then the composer has the guts to write into the score that "my music sounds better if it's sung correctly". I wish he had not done that, it puts the performer under almost unbearable pressure. We all know Berg did not leave us an easy score.

\section{I am now at song number nine}

As a performer I have to be loyal in my communication. To whom? Should I be loyal to the audience? Should I be loyal to the composer? Should I be loyal to the orchestra, the pianist, the conductor? Together with whom should I do the piece? It takes an interpreter, that has a certain amount of experience, to deal with these questions. And to have things put in a very good order up here in the head. For our art to survive, if I dare to say so, we need to ask our students to be much more clear on these subjects.

I hate to say that someone is more suitable to stand in front of an audience than another, but there are differences. We should never think that it's only the quality of one's voice that matters. It's our ability to communicate with an audience that tells us if we should be performers or not. Not to mention the ability to communicate through only the words. You can learn to sing a song from memory and you can sing it many times. Then you try to read the words, read the poem, and you need a piece of paper to remember them. This is an example, stolen from professor Thöres Teorell, who is using the difference between having all the other circumstances around, especially lights and props and all that which you have on an opera stage to make the audience 
understand what you are doing and to have nothing of all that. But it is also very important that singers learn to transmit the message only through the words.

NN: This is something that we have not talked about yet today, I think, but maybe we will hear more about it tomorrow. I would like to hear more about your opinions about the words in the music. What importance have the words? Sometimes in chorus pieces I loose the words, but only because I don't speak Danish that well, but words and music are also so interactive, that it's hard to follow what actually the words say. Then we can maybe bridge over that problem by using some other methods to emphasize the words in programs or whatsoever.

\section{Song number ten is about the process}

For a performer, a singer, to transmit the message, the work that the composer has done, it's very important to let that be a process. The performer should not have the responsibility of producing a result immediately. Therefore, I'm always trying to get involved in the decision chain of a production as early as possible.

When we did "The Ghosts of Versailles" at the Met, an opera by John Corigliano, I went there very early, and I asked about two years in advance for information about what this piece was going to be like. Whatever information you can produce will help us to be prepared when we arrive eight weeks before the opening night. I would like to see costume sketches as soon as they are done, I would like to have a rehearsal tape, which was actually produced on a synthesizer with a student group singing the parts, so we could have a picture of the whole thing. Such a tape is very useful.

I'm constantly fighting for the performing artist to be part of the decision chain much earlier than is usually the case. Not to be treated as an instrument that you just take in your hand and start playing on. You cannot take the human being in your hand and say "sing". The singer must go through a process.

Also the students have to realize that they should start much earlier when they are about to learn things. My teacher, Tito Gobbi, said that for a major part you need a preparation time of four years, no shorter. Spend four years with "Don Giovanni" before you sing it. Today students or singers are lucky if they get three, four months. This is very much contrary to how composers want their pieces to be treated.

It is also important to have the opportunity to meet the com- 
posers, talk to them, interact with them and ask questions. It took me a long time to make Ingvar Lidholm change one dynamics for me in "The Dream Play". It concerned the song where Lidholm says that the short life will disappear, "Det korta livet förgår". When I sing "disappear" or "förgår", the word is filled with pain, and I told him that I would like a subito piano there. And he said, "Fine, you can have it. But that's the only thing you get". He bought that, so this shows that we should be much closer to the composers from the beginning.

Composers and singers don't very often speak the same language. This has to do with us not meeting often enough. We don't talk often enough. This must mean - and, please, argue with me - that composers also have great difficulty in anticipating what the performer will do with their piece. If we know each other better, chances are that performers will more accurately understand and perform the intentions of the composers. That is the future for performing.

I have listed a few wishes to conclude my speech:

I want a lot more to be expected from the interpreter. I'm talking mostly about singers.

I want the singers to be much more responsible for the opera performance.

I want less technique in performances. I think it prevents the fantasy of the audience to work.

I also want less technique in singers' voices and more soul.

I want smaller arenas to perform in, in order to enhance my communication with the audience. I don't want them to sit further away from me, I want them closer.

I want to emphasize on the artist, the performing artists' other roles in society than just performing music and sing. By that I mean to go out in schools, meeting classes, meeting politicians, meeting other people in the society, to talk about what they are doing, and to learn from them what they are doing. This is helping the performing artist to do a better job on stage, because he gets a greater distance to his own achievements and that makes him perform better.

I want composers to perform their own pieces. This has to do with my wish of getting closer to the composers.

I would like the interpreter more often to become a composer. I would like to encourage artists, singers, to write songs that would make them understand much better what composers are doing.

I also, and this is the last, want the artist to take more of a total 
responsibility of what's going on between stage and audience. By that I mean that you should be able to produce your own concert from the very beginning, setting the program, renting the hall, printing the program, doing the economy, marketing, doing the performance, the lights, the press, and so on. This I think will also improve the quality of the performances for the future. Thank you.

- Very concrete, very specific and inspiring. Do we have comments? Yes, please?

NN: Yes. In America people were upset because a woman singer was supposed to sing a text with a male character; did you think that this gender state of the performer is a big problem? I mean, there are a lot of songs, I think, lovely songs that male singers cannot sing, and the other way around, even more songs that women singers cannot sing. It's a pity?

HH: Yes.

NN: So why cannot we skip this bullshit talk and just sing whatever songs we want to sing? Never mind the text, I mean. The way it is now you miss so much music.

HH: I don't know if I understand you right. Do you mean that the text is of less importance?

NN: No, not less importance, but you should trust the audience to read the poem and think that for instance...

$\mathrm{HH}$ : Oh, I see what you mean now.

NN: The Winterreise is supposed to be sung by a man, but OK, it's a woman singing on the stage. It doesn't matter, as long as she sings very well and it will not hurt.

HH: Well, that's a specific problem. I feel very strongly that men should sing men's songs and women should sing women's songs. But, of course, a woman might sing a men's song cycle or song with a lesbian approach to the song. Then it's fine. But she should not pretend that she doesn't know what it's all about, giving the audience a feeling that she doesn't know what this is about. So that's very clear.

When it comes to understanding what we are singing, I think it's absolutely a must that we have to sing in a way that the audience understands the words, otherwise it's not a song. Otherwise it's just music. We can do a vocalise or something that doesn't have a meaning in words. To achieve this is of course to ask the singers to learn how to sing so that the words are audible. But, in my view, the audience should also take a little more responsibility by studying the pieces beforehand. Concert houses should send 
out the programs months ahead, and say: "These are the texts, you can find the books there and there, all the necessary information." That would also make people read more poetry.

NN: That was one proposal you said, but can you explain why it's so difficult to attract the audience to Lieder recitals. I mean, my experience of thirteen years in a concert hall is that traditional repertoire attracts fewer people. You remember we had a series of six concerts during the Stockholm Culture Festival...

HH: Right.

NN: ...with fantastic singers, Dave Johnson was there.

HH: But it was half full.

NN: Yes.

$\mathrm{HH}$ : I think that one big problem is that we are performing in foreign languages, which the audience doesn't understand. With a string quartet language is no issue, we just take in the music. I have an example of choreographers that set choreography to "Winterreise" without knowing what it was all about.

NN: Or don't we have the right rooms, halls for Lieder recitals?

$\mathrm{HH}$ : No, I think we do, but we have to sing much more of present-day literature, that deals with things the audience will recognize. "The Linden Tree", fine, but "Linden Tree" is far away from at least the young audience today. Then I think we should also work on handing out the text to the audience, so they have a chance to study it and understand better. And in schools we should educate an audience for the future.

NN: We are always so puristic, songs should be performed exactly the way they were written and so forth. Should we in this country sing all the Schubert Lieder in Swedish?

$\mathrm{HH}$ : No, I don't believe in that. I think we should, instead, sing a lot more Lieder in Swedish, songs that are composed now. I started a project in Oslo, called the New Song Book of the Oslo Academy. We have collected music from year 2000 and onwards, 35 pieces in all and on Norwegian text. They are all premiered by the students there. The composers can be from around the Nordic countries.

Now, there we come also to the question of who should order music from the composer. For a performer that can be terribly expensive. I have ordered only one piece by Lars Johan Werle. It cost me a lot of money, but his song "En hög visa" I commissioned. I wish I could go around and say: "I need a song cycle for God's sake. I need something that I can perform with a piano and the orchestra. I need more material." Christian Lindberg premiered 63 new trombone concertos. Wonderful! 
But what do we singers get now? Not enough! So that is one of the problems.

HH: I am singing for an audience, and I want the audience with me on this fantastic journey.

NN: But there are audiences and there are audiences. You said that a performer has the right to change things, but as soon as he doesn't communicate with the audience he looses that right. What if the audience is a bunch of idiots that particular night? Would you abandon your approach because you think that the next time it might be the same audience. I mean there is a chance that they will respond after all. Would you change your approach to a better determination?

$\mathrm{HH}$ : Absolutely. If I go somewhere and the concert promoter has approached the wrong audience, an audience that doesn't know anything and doesn't want me to come there, I'm certainly not coming back.

NN: Let's say you were in Stockholm and it didn't work whatever interpretative decision you made. This is what you said, you said you loose the right if it doesn't communicate and next time you are singing in Copenhagen, and would you try it again? Or would уои ...

$\mathrm{HH}$ : I would certainly have a couple of goes at it and see if I can improve it, if I can actually win the audience. But if I don't win the audience with what I'm doing, then I should not continue with it.

NN: So there are audiences and there are audiences.

$\mathrm{HH}$ : Yes, and there are performances and there are performances, and there is me being successful and maybe not so successful. There is a difference from day to day, too. We talked about the frame before. If we keep it within the frame and not get crazy about it and try to win the audience by firing a rocket, you know, and see that this frame, this interpretation, or this type of music, or this text or whatever, it doesn't work. Then we should put it aside and say, thank you, I'm going into something else.

$\mathrm{HH}$ : A question came out of my own experience of sometimes feeling that the opera intendant owns me, and I am there to do whatever he says.

$N N$ : Of course he comes down to the money.

$\mathrm{HH}$ : Exactly, he decides everything. He gives me a very awkward feeling concerning my artistic integrity. I would rather be owned by the audience. They should be my friends. When you 
play or sing for the box office, you get paid every day to come to the hall, so you feel quite good. You feel even better if you are not paid at all, because then you have no guilt for performing. Many festivals today are done that way. They don't pay the artist. They pay for travel expences and hotel rooms, and maybe for the family and so on, and under such circumstances creativity is at its most. And the reason is that the artists are not loaded with guilt, charging money for their performance. Interesting!

\section{NN: What is HageGården?}

$\mathrm{HH}$ : The music centre has a staff all year around, it has 13 hotel rooms, double and single, 23 beds in all. It has rehearsal rooms, it has a recording hall, which is a studio of 300 square metres and 12 metres to the ceiling. It has a recreational part, Jacuzzis and sauna and so on, a golf course nearby, moose hunting and whatever you like. And the way it works is that you call and say that you would like to spend two weeks there studying your piece. Or you would like to bring an ensemble to try out something new. People come from orchestras, they might be burnt out, they need a quiet place. I give a lot of courses, classes and other teachers come and give classes, courses come and ...

$N N$ : Special seasons or?

$\mathrm{HH}$ : All year around. It's not only for music, anybody is welcome. A lot of industry people are coming there for their meetings. Sometimes they sponsor musicians to have their own week at the same time. There are all kind of layouts. At first, twelve years ago when we opened, people thought that only world famous artists were allowed to come there to create something in secrecy. That is certainly not true. Anybody is welcome. One of the most interesting seminars we had was together with Cirque du Soleil from Montreal. I went up to Montreal to study their rehearsal manners. I knew the choreographer very well through collaborations at the Met and in Chicago, and she and I agreed to do something. She brought four acrobats and I brought musicians and dancers from Sweden, and we turned the music centre into a melting pot. Out came a performance that you wouldn't imagine. It has given some imprints on performances since then. So experiments, a meeting platform is what the music centre is about.

HH: I invited a string quartet once, and told them that they could have a week free of charge at the centre. To see if we could find something together. So they came Monday morning at nine o'clock and unpacked the instruments and said: "where is the mu- 
sic?" I said: "There is no music." So they got angry. I said: "We are here to look for the music, to look for ideas, so help me." And they started, hmmm, on Tuesday they had calmed down a little, they opened their ears and their eyes and ideas started to come. On Wednesday they had found some music and sheets and put together, and started to play in a way I had not heard before. Thursday we rehearsed, and Friday we had the performance. We have to break up this tunnel seeing.

NN: Well, that reminds me of Ảke, speaking about recitals a couple of days ago, if they were popular or not popular. It reminds me of the fact that recitals are still very popular. Maybe not the repertoire you are singing. There are lots of people singing, for instance Eva Dahlberg, doing music by Hillborg. I can sell out many halls in many places, Elvis Costello is also a singer. So there is also a kind of change of course in the general culture, that means there are experiments going on and things happening, that are not what we call the classic traditional concert as such, or probably not. Of course we have a problem with our songs, at least at the University of Göteborg. The university will soon have to put out the department of German language.

$\mathrm{HH}$ : Yeah. I agree with you and I think Eva is representing another scenario, doing the right thing. We should do more of that. I am talking about vocal series around the world, even Lincoln Centre has to cancel their series, because they don't get an audience. Even Lincoln Centre has now accepted to do Lieder recitals that are somewhat staged. So, that's one way of going about this problem. The problem with Eva and Anders' work is, that we must not be led into thinking, that if we just do something extreme and new, and if we perform at the central station in Stockholm and so on, we will have solved the problem. I don't think so. An event like that is more an eye opener, that says: we have a possibility. Then we should go in and work hard at that type of performing.

$N N$ : In my view, if I don't misunderstand you, I think you are also a little too mainstream. Isn't it also very important for you, a very important representative of the public classical repertoire, to continue to bring that repertoire to people. If you and your colleagues don't do that, people of the next generation will not have access to it at all. We are in a very small field and you composers that don't compose mainstream music, you have to go on with that, because if we loose you and we loose us, the interpreters, people in the next generation will not have it. And we will end up with, with all respect, only Benny Andersson. 
$\mathrm{HH}$ : Right. If we can have it the way I mentioned at the end, if we let the performer take more responsibility of the whole production, we can do it that way. But as long as performers are hired by concert promoters, saying that, they have a vocal series and they would like you to perform a recital, performers are in the hands of that promoter.

NN: Yeah. OK.

But you still are very much in favour of singing your Lieder cycles and so forth, perhaps packed in another folio?

$\mathrm{HH}$ : Yes, and preferably also a lot of newer music. So we can present something new, because even now you can see that our tenors and baritones, who are performing Lieder, prefer to perform "Winterreise". "Winterreise" is number one. And then the promoters at the Ravinia Festival say, well, we have five other baritones doing "Winterreise" this year so, ... and the audience cannot take that much. We need new things. But I do blame ourselves, though, that since the era of Fischer-Diskau and Schwarzkopf we have been sleeping. Everything is fine, this is going to last forever. I mean, that era of Lieder singing was not created by itself. They worked really hard for it, and I think we should work hard for it, too. We are too lazy as singers.

NN: Let us go back to what we talked about earlier. We said: do we need new halls? We said, no, the halls are there. But, the halls are there, the audience is somewhere else. So, would it not be possible for you to skip these halls and go out where the young audience is? Because if you order a new text from a poet who is hot right now and you get wonderful music, but the concert is in this hall, the young kids will never come. So you have to re-think it, I think.

HH: I totally agree. We already do. In Oslo, for example, we perform in cafés and small pubs and venues around. I take my students down to the Teatercafé and perform there Friday afternoons in order to let the students and the school come out on the town. And I say to them: "The performance in the café is exactly the same as in the concert house." In Stockholm you go to what is called Forum and all these smaller places, the old coal cellars in Vasastan, for instance, and do your performances and there are packed houses. There we find the audience.

NN: You are absolutely right. Now, about these small venues that I want, we need help to create those, too. For example, the one who is in charge of the concert house might not be so happy with this. So maybe we should talk about this in a longer term, saying that this is part of the project. I do attend concerts. I did smaller venues 
in Stockholm this year. Next year I will do a recital at a concert house. Let's see what happens. Ideas like that could be very well explored.

$\mathrm{HH}$ : It's much more a problem for the brain than for the voice. So there it has to do with the training of the singers, to actually be able to manage different circumstances without panic. You know, as soon as there is a window open, there is panic. There is no physical danger, really. It's fear. That's why I emphasize mental training so much. I think we need to look into that, certainly singers do. That way many more of us will be able to perform.

NN: I think there might be a tremendously big gap, a void that we composers and performers together could fill or try to fill, because I don't feel that Elvis Costello is a good enough substitute for, for instance, newly written good music with singers. And speaking about the relationship between composers and singers, I have the impression that, let's say in the last 20 years the close relationship between composers and text has been in some way broken and there is very little focus and emphasis on the relationship between text, music and rhetoric in the education of composers today. So there we have one of the aspects of the problem or trouble of finding good music with texts today. So maybe you should invite ten composers and ten singers and lock them up in your place for a week and then see what comes out of it. Composers need, in order to understand fully how to write for singers, to meet and listen to and be screemed at by singers, because that's a way to learn to write. And to interest themselves for texts and the full literature. I mean, that has been lost in a way, too. So that would be a task for you to start on, and since...

$\mathrm{HH}$ : Can I test something there, because one of the problems is, that most composers say there has to be a commission before we do anything. Who can I ask to commission the pieces, as a performer? No one! I cannot go anywhere and say: "I need a song cycle." The answer would be: "Sure, but 200 others want something too." So that's a problem, a monitoring problem.

NN: That's one of the problems of course, but there should be at least some composers who are really interested in creating for the joy of creating and finding out some new things. And about the form for meeting opera, new opera and new songs, I think this concept of putting it in more intimate settings is the only way to go forward.

Yeah, affordable.

Affordable and close, and much easier for the audience of today 
to understand the energy of opera or the energy of texts that are sung. So, you just look up some composers.

HH: Yes, and I will. I will announce this a lot more and raise the question a lot more, challenge the composers. I think we could find a different form also saying that, if you do that, I do this, and together we perform it and we might even get paid somewhere, you know. Let's do a project together. I have been approached by composers who actually want to compose together with me, that I would be part of the process and I find that's very interesting. The problem is also to find really good texts, newly written, good texts that can be set to music. I would like to put that question to you: "Is it possible to compose music on just any text?"

NN: No.

I was a little confused when you stressed the fact that composers don't compose if they are not commissioned. I think I can find many examples of the opposite. I think my services are rather good examples in many of those things we are talking about now.

A couple of years ago I read poems by Göran Sonnevi, a very famous Swedish poet, and those poems were so fascinating and struck me so strongly, so I had to make a song cycle of the text. I selected, of course, texts from the book, which is rather dark. And the singer I was to write it for, was a singer that I had collaborated with in a rather large role in my second opera. So I made it, and there it was, together with a very famous Swedish singer in this book, and now a recording is made. My example shows that you have to want to do something. That is not as easy as to sit and wait for someone coming to ask you. A composer must have the aim to do things like that, too. $T$

HH: That happens, I am not saying it does not, but I also see that there is a big problem. I meant that, when I ask a composer to write something, he is likely to say: "Yes, if you come with some texts". And then I suggest ten different texts, one after the other, and his answer is "no, no, no, no".

NN: There are a lot of composers who have read texts.

$\mathrm{HH}$ : I think it's something of a marketing thing, too. As you said, we do know the need, but the fact is there: there are very few song cycles written for singers today. And there is a lot of trombone material. So I would like more material, in order to have these recitals going.

NN: I also would want to give a testimony, because I have an experience that composers are definitely very interested in doing these things. From my job we launched a competition in order to inspire composition of new Swedish coral music, and I am not say- 
ing that having a competition in music is the right thing to do. However, we did launch it and there was a deadline on the 1st of September. 59 new works have come in, which I think is tremendous. 59, not all of them gold pieces, but perhaps 40 would be worth performing. I think that is very fantastic. So the composers definitely are interested. In this case they want to be performed and they want to get the first prize. 
PHILOSOPHICAL AESTHETICS AND AESTHETIC THEORY:

PAST, PRESENT AND FUTURE 